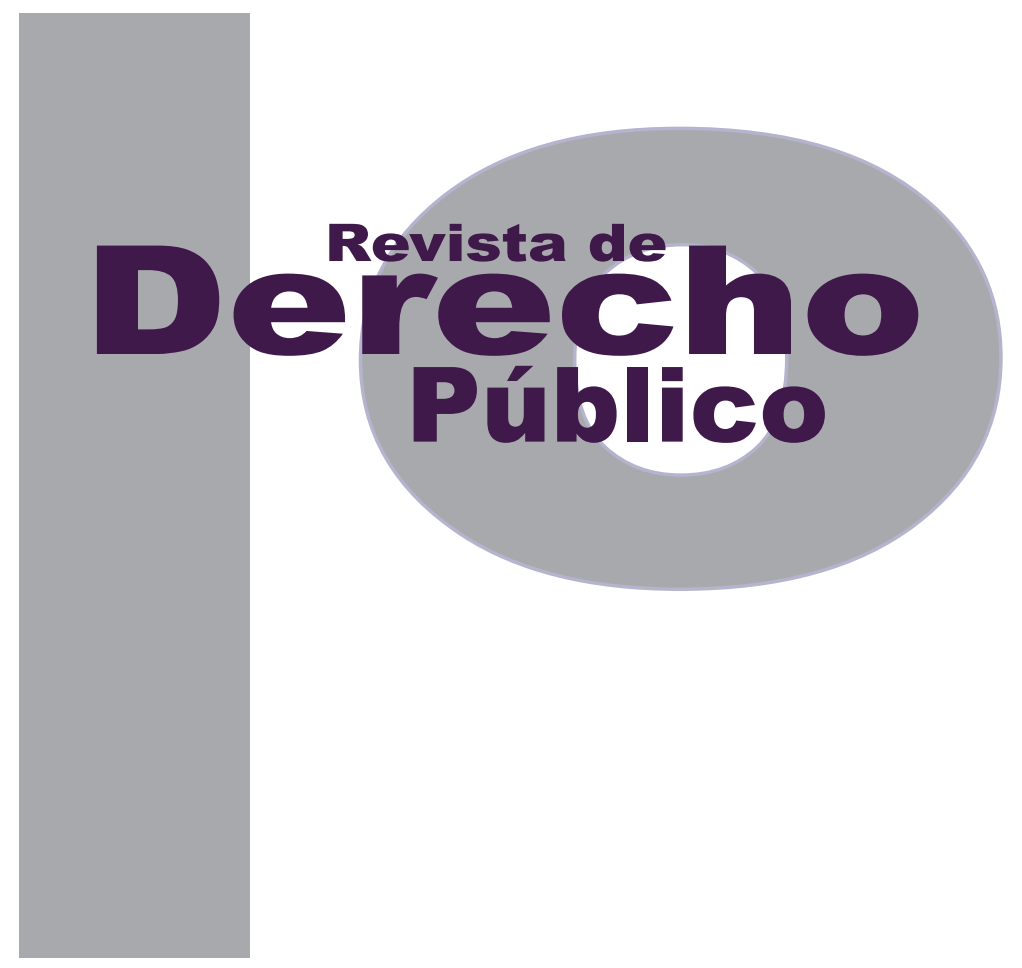

\title{
MEMORIA Y VERDAD JUDICIAL EN COLOMBIA: LOS PROCESOS DE JUSTICIA Y PAZ
}

\author{
FARID SAMIR BENAVIDES VANEGAS
}

Universidad de los Andes

Facultad de Derecho

Revista de Derecho Público N. ${ }^{\circ} 31$

Julio - Diciembre de 2013. ISSN 1909-7778 


\title{
Memoria y verdad judicial en Colombia: los procesos de justicia y paz*
}

\author{
Farid Samir Benavides Vanegas**
}

\section{RESUMEN}

En este texto quiero ocuparme de analizar, primero, la relación de la verdad judicial con la memoria, y la capacidad de aquella de producirla. Esto es, ¿puede el proceso judicial producir verdad y, por tanto, puede esa verdad servir de base para la producción social de memoria?; segundo, las particularidades del proceso de justicia y paz, creado por la Ley 975 de 2005, y el hecho que en ese proceso no hay confrontación para la producción de la verdad, sino la producción estratégica de una verdad, la del victimario, con la notoria ausencia de la verdad de las víctimas. Para ello analizaré de manera muy puntual las declaraciones rendidas por dos de los victimarios dentro del proceso de justicia y paz, y una carta de uno de los comandantes pa-
In this paper I wish to analyze the relationship between judicial truth and memory. I want to answer the following question: Can the prosecution produce truth and, therefore, can this really be the basis for the social production of memory? I also want to analyze the characteristics of the process of justice and peace, created by Law 975 of 2005, and the fact that in this process there is no confrontation for the production of truth. On the contrary, in this process there is a strategic production a truth, that of the perpetrator, with the notable absence of the truth of the victims. To do this I will analyze the statements made by two of the offenders within the justice and peace process and a letter from one of the paramilitary commanders. In all of them I want

Cómo citar este artículo: Benavides Vanegas, F. S. (Diciembre, 2013). Memoria y verdad judicial en Colombia: los procesos de justicia y paz. Revista de Derecho Público, 31.

PhD. Profesor Asociado. Director del Área de Derecho Penal, Procesal Penal y Criminología de la Facultad de Derecho, Universidad de los Andes. Correo: fs.benavides@uniandes.edu.co

Este texto forma parte de un trabajo más amplio en el que me ocupo de analizar las relaciones entre memoria y verdad judicial en el proceso de justicia transicional colombiano. 
ramilitares. En todas ellas me interesa mostrar los argumentos exculpatorios que se esgrimen y la posibilidad que tales argumentos tienen para la producción de verdad y de memoria.

PALABRAS Clave: justicia transicional, memoria histórica, verdad judicial, proceso de justicia y paz. to show the exculpatory arguments that are put forward and the power that such arguments have for the production of truth and memory.

KEY WORDS: Transitional Justice, Historical Memory, Judicial Truth, Justice and Peace Process. 


\section{SUMARIO}

Introducción - I. MEMORIA COLECTIVA Y MEMORIA HISTÓRICA - II. ¿PUEDE LA JUSTICIA PENAL DAR CUENTA DEL PASADO? - III. VERDAD JUDICIAL Y MEMORIA - IV. LA VERDAD EN EL PROCESO JUDICIAL DE JUSTICIA Y PAZ - V. CONCLUSIÓN: LOS LÍMITES DE LA VERDAD JUDICIAL COMO MEMORIA HISTÓRICA - Referencias 


\section{Introducción}

En el año 2005, el Congreso colombiano aprobó la Ley 975 que incorporaba una serie de mecanismos que buscaban hacer frente a los crímenes cometidos por los miembros de las Autodefensas Unidas de Colombia (AUC). Si bien en un primer momento se quiso que dicha ley se enmarcara dentro de la tradición de perdón y olvido que había caracterizado a los actores armados de los procesos de desmovilización del pasado (Benavides y Ospina, 2013), las normas de derecho internacional y la presión de las organizaciones de derechos humanos, que actúan dentro de un ámbito de gobernanza global más estricto que el de los años 1990, obligaron a que el proyecto de ley no fuera de alternatividad penal -como se llamó en un primer momento-, sino que se incluyeran mecanismos de justicia penal, de reparaciones del daño causado y de construcción de memoria, en este último caso con la creación del Grupo de Memoria Histórica (Ospina, en Benavides y Ospina, 2013).

Uno de los aspectos más interesantes de la Ley 975 ha sido la obligación que establece de preservar la memoria del pasado, no solamente con el trabajo del Grupo de Memoria Histórica -que recientemente presentó su informe-, sino con los relatos que surjan de los procesos judiciales. Así, los artículos 56 a 58 establecen la obligación de proteger el derecho a la memoria de las víctimas y, por consiguiente, el deber de que los archivos judiciales sean conservados para efectos de preservar el derecho a la verdad. Más allá de la confusión entre memoria y verdad que se encuentra en el original de la Ley (que fue reformada en el 2012), lo cierto es que desde su propio texto se quiere hacer énfasis en el potencial que los procesos judiciales tienen para la producción de la verdad y para la construcción de la memoria.

El artículo 56 establece el deber de memoria y de preservación de la memoria histórica, que corresponde al Estado. Por ello, el artículo 57 dispone la obligación de preservar los archivos judiciales, como parte del deber de memoria. Es importante destacar que el deber de conservación de los archivos no se limita a los archivos de justicia y paz, ni siquiera de la justicia penal, sino a todos los archivos judiciales, pues en ellos se puede encontrar la historia del despojo de tierras y, sobre todo, la historia de la actuación estatal para proteger a las víctimas de graves violaciones a los derechos humanos. Pese a que es una obligación específica de la rama judicial y de la Procuraduría General de la República no conozco ninguna iniciativa estatal para cumplir con ella. ${ }^{1}$

El espacio de la memoria es un espacio de lucha política entre memorias rivales. Se disputa no solamente acerca de lo que se recuerda, sino también acerca del significado de los recuerdos. La memoria busca asignar responsabilidades,

1 Debe recordarse también el contenido del artículo 30 de la Ley 1621 de 2013, conocida como Ley de Inteligencia Nacional, que dispone que los archivos del eliminado Departamento Administrativo de Seguridad (DAS) sean depurados por una Comisión que, a la vez, tiene la función de preservar la memoria histórica. La importancia de estos archivos no puede ser sobredimensionada, pues tienen en sí la historia de la persecución. Que sean preservados una vez depurados muestra, precisamente, el poco interés en conservar la memoria de la actuación del DAS. 
pero también comprender las causas del conflicto, los acontecimientos que se presentaron, en fin, las razones de la victimización. Por el contrario, el proceso penal se ocupa de la verdad, la cual es el producto de estrategias de confrontación en las cuales surge la verdad de lo acontecido, que es una verdad construida, pero cuya racionalidad está garantizada por el procedimiento (Habermas, 1998).

En este texto analizaré, primero, la relación de la verdad judicial con la memoria y la capacidad de aquella de producirla. Esto es, ¿puede el proceso judicial producir verdad y, por tanto, puede esa verdad servir de base para la producción social de memoria?; segundo, las particularidades del proceso de justicia y paz, creado por la Ley 975 de 2005, y el hecho que en ese proceso no haya confrontación por la producción de la verdad sino una producción estratégica de una verdad, la del victimario, con la notoria ausencia de la verdad de las víctimas. Para ello me ocuparé de analizar de manera muy puntual las declaraciones rendidas por dos de los victimarios dentro del proceso de justicia y paz y una carta de uno de los comandantes paramilitares. ${ }^{2}$ En

2 En este texto no me ocupo de analizar en detalle todas las declaraciones de los procesados por Justicia y Paz ni todas las declaraciones de los postulados seleccionados. La selección de Evert Veloza, alias $\mathrm{H}$. H., responde al hecho que es el procesado que se considera el más sincero en sus declaraciones, esto es, quien realmente ha dicho toda la verdad. Sin embargo, su declaración no difiere de la de Raúl Hasbun ni de la carta de Ramón Isaza. Podría haber utilizado otras declaraciones, como las de Salvatore Mancuso o las de Hernán Giraldo, pero para los propósitos de este artículo no ofrecen nada diferente a lo que ya aportan los materiales seleccionados. En este análisis sigo el modelo de investigación de Leigh Payne en su libro Unsettling Accounts. Podríamos cuestionarle a la autora que su base empírica es deficiente, pues solo recoge el relato de Adolfo Scilingo y no el de los miles de victimarios que hubo en la dictadura argentina. Sin embargo, una acusación tal simplemente no entendería cuál es el propósito de su trabajo y cuál es el sentido de la investigación cualitativa. todas ellas me interesa mostrar los argumentos exculpatorios que se esgrimen y la posibilidad que tales argumentos tienen para la producción de verdad y de memoria.

Como lo señalaba la magistrada Alexandra Valencia, de la Sala de Justicia y Paz del Tribunal Superior de Bogotá, el proceso de justicia y paz es un proceso acordado, y en esa medida su verdad lo es también. ${ }^{3}$ Es decir, las preguntas que conviene hacer son: ¿puede el proceso de justicia y paz producir memoria del conflicto? ¿si lo es, cómo?, y en últimas, ¿cuál es el valor de la verdad judicial como un mecanismo de justicia transicional?

\section{MEMORIA COLECTIVA Y MEMORIA HISTÓRICA}

La memoria es parte de la construcción de las naciones en la modernidad. Como lo ha señalado Anthony Smith, los procesos de construcción de nación parten de la base de un recuerdo y de un olvido. El recuerdo de un acontecimiento fundador de identidad, y el olvido del exterminio y de la exclusión de grupos enteros de población (Smith, 2000; Miguez Macho, 2012; Benavides, 2006). En consecuencia, la memoria y el olvido son aspectos fundamentales en el proceso de construcción de nación. Sin memoria no podemos recordar las gestas del pasado que determinan nuestra identidad, pero sin olvido tampoco podríamos sobrevivir como nación, pues de manera constante estarían en nuestra memoria

3 Conversación con la magistrada Valencia, en julio de 2013. 
los agravios sufridos en el pasado. En el genocidio de la antigua Yugoslavia y en el de Ruanda, para citar solo dos ejemplos, los relatos sobre los agravios sufridos servían de justificación para los crímenes cometidos.

La memoria, como mecanismo creador de identidad, tiene un papel fundamental en la construcción de un sentido de pertenencia de los sujetos a un grupo determinado o a una comunidad (Jelin, 2002). La discusión sobre la memoria en los procesos de transición puede encontrarse con posterioridad a la II Guerra Mundial. Como lo ha señalado Bietti (2008),

Ios debates sobre la Segunda Guerra Mundial relacionados con el exterminio nazi impulsaron el surgimiento de los discursos sobre la memoria, que a partir de la década de los ochenta comenzaron a tener gran presencia dentro de diferentes sociedades. Empezaron a surgir muchos "Holocaustos" en diferentes partes del mundo (Armenia, Ruanda, Guatemala, etc.) en los cuales los discursos sobre la memoria acerca de periodos represivos y de violencia política funcionaron como uno de los pilares para la construcción de órdenes democráticos en los que los derechos humanos estén garantizados para toda la población, independientemente de su clase, raza, género, orientación ideológica, preferencia sexual, religión o etnicidad.

La memoria se ha entendido de diversas maneras: como un sustituto de la historia, como una forma de traer al presente el pasado de las comunidades o como un complemento de la historia. En España, algunos autores han querido introducir una discusión con respecto al calificativo de la memoria. Para estos, la memoria es por definición histórica y, por esta razón, no cabe hacer la distinción entre memoria histórica y memoria colectiva (Bergalli, 2010, 2012; Bietti, 2008, 2011). Sin embargo, es preciso tener en cuenta que por memoria colectiva con frecuencia se ha entendido a la memoria que comparten los grupos y que aún no ha sido elaborada como discurso histórico; en tanto, la memoria histórica es precisamente la elaboración discursiva del pasado (Benavides, 2013a; Aguilar, 2008, 1996).

Sin embargo, una es la incorporación que las comunidades hagan de los hechos del pasado y otra el significado que se le atribuya a tales hechos. Estos significados están sujetos a constante cambio y no son necesariamente compartidos por todos los miembros de las comunidades. Además, la construcción de la memoria puede también ser objeto de procesos de cimentación de hegemonía o de violencias hermenéuticas $\mathrm{y}$, por consiguiente, la memoria particular de un colectivo presentarse como LA memoria o, incluso, como LA memoria histórica (Benavides, 2004).

La memoria como tal se convierte en un aspecto significativo de la construcción de la paz y de la comprensión del conflicto. La memoria permite que los grupos compartan un sentido de pertenencia común y tener una identidad colectiva a través del recuerdo y del olvido. Dado que la memoria está conectada a la cuestión de la identidad y de la historia de un grupo, es con frecuencia objeto de revisión y de disputas. La memoria puede ser perpetuada a través de procesos como la memorialización, la construcción 
de monumentos nacionales y celebraciones conmemorativas que permiten a las sociedades divididas reescribir su historia y sus narraciones del pasado, y a las víctimas de graves violaciones a los derechos humanos comenzar su proceso de reparación simbólica y dar inicio a los procesos de reconciliación, a través del reconocimiento de grupos tradicionalmente oprimidos y olvidados (Naidu, 2006).

La memorialización toma varias formas y es un concepto que sirve para recoger diversas maneras de recordar y de conmemorar. La memoria no puede ser suprimida, por más que muchos gobiernos intenten reescribir la historia, ella resurge de un modo o de otro. Lo que buscan los proyectos de memorialización es que la memoria surja de una forma positiva, esto es, que permita no solo recordar a las víctimas, sino evitar que los hechos del pasado se repitan en el futuro. La memorialización es así un proceso que satisface el deseo de ser reconocidos y de que nuestra memoria sea honrada; que dignifica a aquellas personas que han sido víctimas de graves abusos a sus derechos y se convierte en una forma de reexaminar el pasado. En este proceso, el pasado puede ser reinterpretado para dar respuesta a una serie de necesidades políticas y sociales. La memorialización es así concebida como un espacio de disputas de significados, y de disputas acerca del significado de la memoria, en el que se ofrece la posibilidad de ayudar a la formación de una nueva nación, una nueva comunidad o una nueva identidad étnica. De acuerdo con Mneimneh, el recordar el pasado es por necesidad transformador de ese pasado que se recuerda, subjetivamente se destacan unos aspectos sobre otros, puede incluso ser percibido como una confiscación de la historia. Por ello es tan importante que en el proceso de recuerdo del pasado se dé la mayor transparencia y participación posible, para así contribuir a una construcción colectiva y democrática de la memoria (Bickford, 1999, 2007; Naidu, 2006).

La memorialización también puede tener un lado oscuro; puede ser usada por los vencedores con el propósito de reescribir la historia y borrar de ella a los vencidos, o puede ser utilizada para mostrar un lado de la historia en el que los vencidos sean vistos como los victimarios y las violaciones de derechos humanos como actos de legítima defensa (Weinstein citado por Barsalou y Baxter, 2007, p. 4).

La construcción de monumentos que recuerden a las víctimas suele ser producto de recomendaciones de las comisiones de la verdad, como en Chile y El Salvador, pero también resultado de procesos que se dan dentro de países que se sienten maduros para enfrentar un pasado que no solo es doloroso, sino que aún puede ser fuente de divisiones, como es el caso de España, en general, y de Cataluña, en particular. Medidas como la celebración de días particulares, la destinación de espacios públicos para el recuerdo de las víctimas, la asignación de nuevos nombres a las calles o la recuperación de los nombres que tenían en el periodo preautoritario, tienden todas a construir una nueva memoria en la cual las víctimas de los crímenes del pasado sean incluidas (Jelin, 2002). 
La construcción de la memoria es patrocinada con frecuencia por el Estado, pero al igual que existen procesos alternativos de verdad, como en el caso de las comisiones no oficiales de la verdad, se dan también proyectos alternativos en los cuales se busca hacer visible el papel de instituciones estatales en la comisión de actos vulneratorios de los derechos humanos y del derecho internacional humanitario (Bickford, 2007). Tal es el caso de las dos comisiones de la verdad de Guatemala: una, la de la Misión de Nacional Unidas en Guatemala (MINUGUA), que se cuidaba de dar nombres y hacer acusaciones, y otra la de la Comisión presidida por monseñor Juan José Gerardi, que mostraba con toda claridad la historia de la represión y los responsables de esta, destacándose en el cuarto tomo los nombres de todas las víctimas (Goldman, 2008).

Tanto el Estado como la sociedad civil reconocen el poder reivindicativo y simbólico de los memoriales, pero es poco lo que se conoce a nivel empírico sobre su efecto reconciliador de la construcción de la memoria. Se corre, entonces, el riesgo de que sean vistos como reparaciones meramente simbólicas que tienen el efecto de desviar la atención de los aspectos materiales de la reparación.

En el trabajo de investigación que el Centro para el Estudio de la Violencia y la Reconciliación de Sudáfrica lleva a cabo se muestran las diferencias entre la justicia transicional y la construcción de los memoriales. Esta diferencia se percibe en la medida en que la justicia se entiende como justicia penal para un periodo de transición y con la finalidad principal de sancionar a los responsables de la comisión de graves violaciones al derecho penal internacional. El discurso de esta forma de justicia se entiende como muy legalista y concentrado en la retribución y la prevención a través de la justicia penal. La tendencia es construir mecanismos que se ocupen de lidiar con el pasado, establecer los hechos a través de investigaciones penales y, en general, realizar una construcción procesal de la verdad. La memoria, en todo caso, aparece como un subproducto y no como la finalidad principal de los procesos de justicia penal.

Por el contrario, la construcción de memoriales es vista como un proceso mucho más detallado y expresamente dirigido a la perpetuación de la memoria con el fin de facilitar procesos de recuerdo y de reconocimiento de las víctimas. Así, la memorialización no es concebida como un substituto de las reparaciones materiales ni una forma de reparación simplemente simbólica. Por el contrario, tiene una variedad de propósitos que apuntan a la construcción de una cultura de paz y a ocuparse de aspectos como la dignidad, las relaciones humanas y la identidad colectiva. De ese modo la construcción colectiva de la memoria contribuye al desarrollo humano y a la regeneración de capital humano que es con frecuencia destruido durante los periodos de conflicto y de opresión.

En muchos casos los memoriales son manipulados políticamente, por lo que es preciso que las iniciativas en este sentido sean producto de un proceso colectivo y democrático, de lo contrario, en vez de ser un mecanismo de justicia 
en épocas de transición, a través de la redignificación de las víctimas y de su historia, pueden convertirse en un nuevo instrumento de ocultamiento y de opresión. Igualmente, el momento y la secuencia son también de crucial importancia, pues pueden contribuir a alienar a ciertos grupos en lugar de acercarlos. De la misma manera, los memoriales deben ser continuamente resignificados, ya que con el paso del tiempo pueden perder su valor y aparecer como figuras vacías para las nuevas generaciones.

\section{II. ¿PUEDE LA JUSTICIA PENAL DAR CUENTA DEL PASADO?}

La pregunta fundamental que surge con respecto a la justicia penal, en su capacidad de dar cuenta del pasado, es precisamente aquella que planteara el juez Robert H. Jackson en su presentación ante el Tribunal de Núremberg. Para Jackson era un hecho fundamental que los crímenes cometidos fueran sancionados por un tribunal penal, pues la humanidad no se podía dar el lujo de ignorarlos ya que en su sanción estaba en juego precisamente la supervivencia de la humanidad misma. Por ello consideraba importante que se sancionara no solo a los criminales menos importantes sino, sobre todo, a los planificadores y organizadores de la guerra, a quienes con sus órdenes fueron responsables de estos crímenes (Jackson, 1947; Hocket, 1990).

Sin embargo, la pregunta no tiene una respuesta tan clara como lo suponía Jackson. En los casos de transición de gobiernos autoritarios, los gobiernos democráticos se han visto enfrentados a la exigencia de sancionar los excesos de la dictadura frente a los riesgos que para la estabilidad democrática ello representa. El derecho penal puede traer algún tipo de justicia para las víctimas, pero esa justicia depende de la existencia de la democracia, que precisamente es puesta en peligro por la realización de los juicios penales. Frente a las posiciones sancionatorias -que algunos califican de idealistassurgen las posiciones pragmáticas o realistas.

Dentro del campo de las posiciones pragmáticas encontramos quienes sostienen la no punibilidad por razones políticas, señalando que el juicio penal puede ser un obstáculo a la transición o a la sostenibilidad de la paz y de la democracia. Dentro de este campo también encontramos autores que, amparados en una argumentación normativa, afirman que el derecho penal no supera el pasado y que precisamente el pasado se supera con una política de perdón y olvido (Jakobs, 1994).

Desde una perspectiva exclusiva del derecho penal se asume que la pena tiene dos funciones, una preventiva y otra retributiva. Existe un consenso acerca del hecho de que la pena no puede ser mera retribución o castigo pues eso implicaría confundirla con la moral, por lo que se afirma la necesidad de que la sanción penal cumpla una función preventiva. Sin embargo, aquí radica el problema para ciertos autores que consideran que en algunos casos es innecesario acudir al derecho penal y a la justicia penal, pues una vez superado el régimen autoritario no hay nada que prevenir y, por lo mismo, 
no es necesario ni legítimo aplicar una pena con fines meramente retributivos.

Frente a la idea de imponer sanciones penales, algunos críticos piensan que se trata de afirmaciones moralistas que no reconocen la necesidad de que haya paz, incluso por encima de la sanción de los responsables. De acuerdo con tales consideraciones, la pretensión de sancionar a los responsables conduce a una paz inestable y desconoce la existencia de las relaciones de poder dentro de los países, lo que impide que se implemente una política de sanciones penales. Sin embargo, al mismo tiempo es necesario tener en cuenta que la pena tiene un efecto preventivo y educativo, y se busca con ella que la ciudadanía y las elites en el poder no solo no cometan delitos en el futuro, sino que encuentren en el hecho de la sanción un factor educativo que les enseñe la importancia del respeto a los derechos que se buscan proteger con la sanción penal. Como lo afirma Akhavan (1998), la no sanción de las atrocidades cometidas contra la población civil -refiriéndose al caso de Yugoslavia- envía un mensaje negativo a los potenciales agresores, indicándoles que tales crímenes pueden ser cometidos con impunidad y, por tanto, terminar brindando estímulo y razones a los perpetradores para que acudan a la violencia en escala masiva, pues aprenden que la violencia es un mecanismo eficiente para alcanzar el poder y que la justicia no hace ni puede hacer nada para detenerlos.

No obstante, la prevención supone la existencia de causas determinadas e identificables del comportamiento criminal que se quiere eli- minar con la sanción penal. Además, presume que el comportamiento sancionado no es normal ni generalizado, pues no tendría sentido que el sistema penal se ocupara de sancionar comportamientos que la sociedad no percibe como negativos, o comportamientos que son tan comunes que desbordan la capacidad de acción del sistema. Tal es el caso de los juicios en Alemania y en Japón. En el primero se resalta el hecho de que los actos por los que fueron juzgados algunos de los abogados y jueces del régimen nazi eran legales conforme a la legalidad alemana. De la misma manera, y este es el caso del cual se ocupa Gunther Jakobs, el juzgamiento de los guardias apostados en el Muro de Berlín y con órdenes de disparar a quienes lo intentaran cruzar, plantea precisamente el problema de la sanción a personas que defendían una legalidad violenta que ya no existe y que no tiene posibilidad de resurgir en el futuro.

En otros casos, como el de Yugoslavia o el de Ruanda, los eventos son el resultado de situaciones excepcionales que precisamente muestran la necesidad de una sanción que demuestre la vigencia de la ley penal, sin embargo, al lado de la sanción penal se precisa de medidas que se ocupen de las causas del conflicto y de la construcción de la paz, pero ello corresponde más a la labor del Estado, en tanto prestador de servicios, que al sistema de justicia penal.

Para Jakobs, la pena se justifica si es posible realizar la imputación del acto a un sujeto como suyo y no como el resultado de hechos que él o ella no pudieron controlar, por lo que también debe ser necesaria para restablecer la vigencia 
de la norma. En su análisis de los juicios de Núremberg, concluye señalando que lo que estaba en juego era un juicio al propio estado nazi y a su legalidad, y esto precisamente conduce a la suspensión del principio constitucional de prohibición de la no retroactividad. Respecto a los crímenes cometidos por los guardias de la frontera en el Muro de Berlín, afirma que los hechos no son imputables como ilegales -la norma era válida dentro de la República Democrática Alemana-; no hay necesidad de pena, pues el régimen ya desapareció; y por ello sugiere que la mejor forma de superar el pasado es a través de una política de perdón y olvido. En cuanto a las víctimas entiende su deseo de venganza, pero afirma que el estado no ejerce venganza y no reacciona solamente contra el daño causado a las víctimas. "El estado reacciona más bien contra el daño a la generalidad, al quebrantamiento del derecho, y ello, por cierto, libre de la emoción con la cual la víctima se dirige como víctima, a su opresor" (Jakobs, 1994, p. 154).

Uno de los problemas fundamentales que enfrenta la justicia penal es el relacionado con el respeto del principio de legalidad. Dado que en estos casos el Estado y la propia judicatura son responsables de las violaciones cometidas por el régimen pasado, el nuevo régimen se ve en la difícil posición de legitimar su legalidad -que desea que sea permanente y estable- a través de una legalidad de transición, que es inestable y, sobre todo, está marcada por la política de la transición. En los debates Radbruch-Hart-Fuller lo que está precisamente en discusión es la idea de continuidad del nuevo régimen y la discontinuidad del pasado, pues no de otra mane- ra se concibe que se juzguen a los funcionarios del régimen derrotado por actos que eran legales bajo la legalidad anterior. Tanto Fuller como Radbruch sostienen que la legalidad pasada no era válida y por tanto no era existente, por lo que los actos de los nazis eran arbitrarios y no amparados por norma alguna; en tanto, para Hart, la norma positiva es válida y por ello mismo es vinculante, lo que impide el juzgamiento de quienes solo se limitaban al cumplimiento de una legalidad violenta.

Dados estos dilemas que pone la justicia nacional, no es casual que se acuda a la justicia internacional y al derecho internacional para dotar de legitimidad a las actuaciones del nuevo régimen. La respuesta de Radbruch al dilema del principio de legalidad apunta a la existencia de un derecho supralegal, que naturalistas como Fuller remiten a los derechos naturales del ser humano. Este derecho supralegal en Radbruch no se encuentra en una idea abstracta del derecho natural sino en el marco legal establecido por el derecho internacional, o por lo menos en proceso de establecimiento al momento en que Radbruch escribía. Así, el derecho internacional se convierte en una fuente de legitimidad y de continuidad en los juicios realizados durante las épocas de transición (Radbruch, 1962).

Los juicios penales realizados por las Cortes internacionales o por las Cortes nacionales pero dentro de un marco de derecho penal internacional, se caracterizan por ser vistos como juicios que buscan superar la arbitrariedad política del pasado, señalar precisamente el imperio de la ley y, por ello, el fin de la política. La ley es 
vista de esta manera como antipolítica, a pesar de que se trata de juicios que tienen un alto contenido político, aunque en este caso lo que buscan es el establecimiento de una rule of law de tipo liberal. El nuevo imperio de la ley sirve para establecer un rompimiento con el pasado y para condenarlo como contrario al mismo y al estado de derecho (Osiel, 2000; Teitel, 2003, 2000). ${ }^{4}$

Como lo señala Human Rights Watch (2009) en un informe en el que analiza el uso de la justicia penal en la transición de varios países, el derecho internacional ha evolucionado en los últimos años a un punto en el que, tanto la paz como la justicia son los objetivos a alcanzar, es decir, que la justicia no puede ser más la sacrificada en los procesos de transición a la democracia o a la paz. En todo caso, los acuerdos de paz se hacen dentro de un marco de derecho penal internacional que impide que la cuestión de la justicia penal caiga en el olvido. La justicia puede ser vista como penosa e incluso inconveniente, pero en todo caso como una alternativa mejor que la impunidad. ${ }^{5}$

4 En todo caso, es necesario señalar que la construcción de la paz y la sanción a los responsables de graves violaciones a los derechos humanos o al derecho internacional humanitario no deben ser miradas como actividades contradictorias, pues si bien la sanción penal puede afectar un compromiso de estabilización de corto plazo, sí cumple una función importante en la construcción de la legitimidad estatal en el largo plazo (Anten, 2009, 2009a). Las concesiones a corto plazo pueden afectar la efectividad del derecho penal internacional y enviar el mensaje errado de que este tipo de conductas graves no serán sancionadas.

5 Frente a las críticas formuladas a la transitoriedad de la rule of law propia de los momentos de transición, quienes proponen la sanción de los responsables encuentran que su legitimidad radica en la continuidad establecida por el derecho penal internacional. Sin embargo, el análisis resulta falaz pues, de la existencia de condiciones normativas para realizar los juicios, concluyen que políticamente es prudente hacerlo. En otras palabras, una es la discusión acerca de la validez de los juicios penales, ya superada en el derecho penal internacional, y otra es la discusión acerca de su necesidad o posibilidad política, dadas
Admitida la validez y la necesidad de los juicios penales para hacer frente a los hechos del pasado, conviene establecer cuál es la finalidad de tales juicios más allá de la cuestión de justicia. Esto es, si los juicios penales nos proporcionan la verdad que se necesita en un proceso transicional y si esa verdad puede servir de base para los procesos de construcción democrática de la memoria.

\section{VERDAD JUDICIAL Y MEMORIA}

El proceso penal es el espacio en el cual se define la responsabilidad de una persona y, por consiguiente, la aplicación de una pena determinada o de una medida de seguridad. De tal manera, el proceso penal es un espacio de confrontación de dos actores con el fin de dar cuenta de la verdad de los hechos objeto de juzgamiento. Como lo señala Thomas Weigend (2003, 2010), el proceso penal se ocupa de la verdad, por lo mismo, resulta relevante la forma en la que se determinan los hechos verdaderos del mismo. Si bien el proceso penal tiene una serie de objetivos señalados, como la búsqueda de un acuerdo entre las partes, la determinación de la pena, etc., lo cierto es que ninguna de estas medidas puede tener lugar si antes no se ha logrado establecer qué pasó realmente, esto es, cuáles son los hechos que permiten deducir las consecuencias previstas en la ley.

En los procesos de justicia transicional, la búsqueda de la verdad es uno de los pilares cen-

las condiciones de la transición y la fortaleza relativa de los actores de esta (Osiel, 2000). 
trales sobre los que se basan los mecanismos no punitivos de transición. "Con el fin de lograr el cierre de eventos traumáticos, parece más importante determinar y hacer público qué sucedió realmente que imponer sanciones penales" (Weigend, 2010, p. 390). Por ello, en este tipo de procesos transicionales se busca que la verdad surja como parte de la no repetición de los hechos, pues en la medida en que conozcamos qué sucedió podremos decir realmente cuáles son las medidas a tomar para evitar su repetición.

Sin embargo, no todos los actores dentro del proceso penal están obligados a la búsqueda de la verdad y, sobre todo, en el proceso penal existen límites para la búsqueda de esa verdad. Es decir, no es posible afirmar que dentro del proceso se deba alcanzar la verdad a cualquier costo. El derecho del procesado a guardar silencio, e incluso el derecho a mentir y a presentar su propia versión de los hechos, nos muestra los límites que tenemos dentro del proceso penal. En los modelos procedimentales tanto anglosajón como continental, la consecución de la verdad con violación de ciertas reglas de procedimiento conduce a afirmar que la verdad no se puede obtener sin más y que resulta necesario que sea alcanzada mediante una actuación válida frente a la Constitución y las leyes (Habermas, 1998; García Amado, 1997).

Los diferentes sistemas procesales hacen énfasis en la necesidad de la búsqueda de la verdad dentro del proceso, pero no definen la naturaleza de esa verdad. Así, podría decirse que la noción que se maneja es la verdad como corres- pondencia, esto es, la identidad entre el sujeto y el objeto en cuanto a la afirmación de lo que es verdadero. De este modo, si X mató a Y, el enunciado es verdadero si efectivamente $X$ realizó la acción de matar a Y. Sin embargo, esta noción de verdad descansa sobre una falacia, pues supone que ya conocemos la identidad entre los objetos para poder afirmar la verdad de los enunciados (Gutiérrez, 1983; Habermas, 2003). Una aproximación diferente es reconocer el carácter construido de la verdad. Sin embargo, el proceso penal se caracteriza por el enfrentamiento entre los sujetos y, por tanto, por la ausencia de cooperación para la producción de la verdad. En el proceso penal los actores buscan presentar su propia versión de los hechos, conforme a ciertas reglas que les obligan a revelar aquello que han averiguado, pero que no les obligan a buscar lo que puede perjudicar a sus clientes -si se trata de la defensa- o que pueda beneficiar el caso del procesado - si se trata de la acusación-. Si se acoge la idea de que la verdad es una suerte de oro que se debe encontrar, entonces lo que la legitima es el resultado y no el procedimiento. Si se trata de una visión constructivista, lo que legitima la verdad producida es el procedimiento y no simplemente el resultado.

Para organizaciones de derechos humanos que se ocupan de la averiguación de la verdad, el proceso judicial no es necesariamente el mejor espacio para su determinación. Así, la opinión del Movimiento de Víctimas sobre la verdad judicial es la siguiente:

La verdad judicial tiene los siguientes problemas. Está circunscrita a un marco legal deter- 
minado que impone sus límites estrictos. En Colombia tradicionalmente se ha denunciado el alto porcentaje de impunidad, se puede afirmar que en el caso de violaciones a los derechos humanos el porcentaje de impunidad es del 99\%, es decir que de cien crímenes cometidos 99 quedan sin castigo o sin enjuiciamiento contra sus responsables. Además, la implementación de mecanismos institucionales de impunidad conformados por leyes que impiden el juzgamiento de militares por parte de los tribunales judiciales ordinarios, la inexistencia de tipos penales (la desaparición forzada fue tipificada como delito sólo hasta el año 2002, luego de más de dos décadas de lucha por parte de organizaciones sociales), la existencia de términos de prescripción que favorecen la prescripción y la preclusión de investigaciones y la sanción de leyes como la 975 de 2005 (conocida como ley de "Justicia y Paz") que establecen un tratamiento preferencial a los paramilitares.

Además la verdad judicial es casi siempre una verdad atomizada, que toma caso por caso de forma aislada, diferenciando la responsabilidad penal de la administrativa y la disciplinaria, y sin contemplar la responsabilidad ética ni la reparación simbólica. Tampoco establece sistematicidad ni conexidad entre sucesos criminales, víctimas ni victimarios. Mucho menos es una estrategia de reconciliación, por el contrario ha sido una estrategia que ha generado más odios.

Esto sin contar con las amenazas y crímenes contra testigos, denunciantes y abogados, la desaparición de pruebas, la infiltración de la fiscalía y el poder judicial. En resumen la verdad judicial no permite desentrañar la lógica represiva que produce los crímenes, no profundiza en "los contextos"; en las opciones de las víctimas y sus proyectos; en el discernimiento de intereses que estaban en juego al ser perpetrados los crímenes; en las constancias represivas de Ios victimarios; en las solidaridades existentes entre los poderes y en la lógica de las cadenas de mando; en el análisis de los controles territoriales; en las rutinas del ocultamiento y la tergiversación que los mass media vehiculan; en las dinámicas del terror y sus secuelas así como en todos los efectos que los crímenes pretendían causar. ${ }^{6}$

\section{LA VERDAD EN EL PROCESO JUDI- CIAL DE JUSTICIA Y PAZ}

La Ley 975 de 2005, también conocida como Ley de Justicia y Paz, estableció un procedimiento mediante el cual se le da relevancia al relato de los postulados, de manera que la construcción de la verdad no es colectiva, como en el proceso ordinario tradicional; se trata de una verdad unilateral, que se construye a partir de los relatos del victimario sin tener en cuenta el relato de las víctimas.

En efecto, en la estructura del proceso penal de justicia y paz se observa lo siguiente: en primer lugar, el gobierno nacional realiza la postulación de las personas desmovilizadas. Una vez la persona es llamada por la Fiscalía, lo que podría ocurrir en un breve o en un largo plazo -muchos

6 Recuperado de http://www.movimientodevictimas.org/ nuncamas/ index.php?option=com_content\&view=article\&id=27:verdad-historicavs-verdad-judicial\&catid=2\&ltemid=608. Última visita 17 de octubre de 2013. Debe aclararse que la desaparición forzada está tipificada como delito desde el año 1999. 
postulados aún no han sido oídos en versión libre-, se la escucha en versión libre y se practican las pruebas necesarias para demostrar la veracidad de sus afirmaciones. Sin embargo, en la mayor parte de los casos se cuenta solamente con las pruebas que proporcionan los propios postulados y la Fiscalía no tiene más remedio que aceptar sus versiones como verdaderas. Las víctimas solo son escuchadas en el incidente de reparación y solamente con miras a determinar la naturaleza y la cuantía del daño sufrido.

Como lo ha señalado la magistrada Alexandra Valencia, de la Sala de Justicia y Paz del Tribunal Superior de Bogotá, ${ }^{7}$ en el proceso penal ordinario se busca al autor de un delito. En el proceso de justicia y paz se busca el delito o los delitos cometidos por cada uno de los autores que han sido postulados. De este modo, la confesión se convierte en la pieza central que orienta el trabajo de la justicia y por tanto en la única fuente de verdad y de memoria para el futuro.

Desde un principio, la Fiscalía trató con absoluta deferencia las declaraciones de los postulados y les otorgó credibilidad no solo para otras investigaciones sino para determinar la naturaleza del conflicto en Colombia. El riesgo de esta estrategia de investigación es que se presente como verdad el relato interesado de los postulados de las Auc, algunos de los cuales ni siquiera pertenecieron a la organización, sino que compraron la franquicia con el fin de obtener los beneficios de la Ley de Justicia y Paz, como fue el

7 Conversación con la magistrada, en julio de 2013. caso de Francisco Javier Zuluaga, alias Gordolindo, expulsado del proceso de justicia y paz. ${ }^{8}$

En el caso de Salvatore Mancuso, por ejemplo, vimos que en los momentos previos a su extradición a los Estados Unidos sugería la participación de miembros del gobierno en las Auc, pero nunca hizo ninguna acusación directa, todo ello con el fin de obtener beneficios por parte de las autoridades. Igualmente, en las entrevistas de radio que concedía insinuaba la existencia de una suerte de teoría de los dos demonios, en donde se mostraba que el fenómeno paramilitar era simplemente el resultado de los abusos de las guerrillas y no parte de una estrategia antisubversiva coordinada por el Estado con el apoyo directo de las Fuerzas Militares, como se ha señalado por diversas personas. Frente a los crímenes cometidos por los grupos paramilitares, Mancuso señalaba la existencia de una estrategia de combinación de todas las formas de lucha, con lo cual se buscaba justificar estos crímenes y, en últimas, basar todo el fenómeno en la teoría de los dos demonios. ${ }^{9}$

Contrario al análisis realizado por Leigh Payne, los relatos de los paramilitares no han tenido un efecto perturbador no solo porque han sido enmarcados en un contexto diferente al de la solicitud de perdón, sino porque han sido formulados dentro de un proceso judicial, por lo cual carecen del valor de meras confesiones y más bien constituyen medios para lograr bene-

\footnotetext{
8 http://www.eltiempo.com/archivo/documento/CMS-12597747

9 http://www.wradio.com.co/noticia/grabaciones-de-salvatore-mancusojefe-de-las-autodefensas/20081219/nota/733834.aspx
} 
ficios dentro de este. Es decir, se trata de testimonios perturbadores (Payne, 2008), no por lo que confiesan sino porque no contribuyen a una construcción democrática de la memoria, solamente a una elaboración estratégica en la que el recuerdo o la reelaboración se convierte en el fundamento de la verdad y por ello de la memoria de ese pasado que ha sido construido dentro del proceso penal. Como lo dice Payne, las confesiones de los perpetradores alteran a los que las escuchan, pues, en algunos casos, por primera vez se enteran de detalles estremecedores y espeluznantes. Estas confesiones perturban, o rompen, el silencio impuesto sobre el pasado por aquellas fuerzas dentro de las sociedades democráticas que anhelan dejar el pasado atrás y cerrar la página. Las confesiones de los paramilitares, sin embargo, no revelan necesariamente verdades sobre el pasado. Se trata de simples informes, explicaciones y justificaciones de un comportamiento por fuera de lo normal, o de versiones personales sobre el pasado (Payne, 2009, p. 27).

Si se observan las declaraciones de los paramilitares se ve que acuden a diversas estrategias de justificación de los actos inmorales, y a distintas formas de disculpar los crímenes cometidos. Por ejemplo, Raúl Hasbún justifica su vinculación a las Auc por los abusos de las guerrillas. Así lo expresa en su versión libre del 23 de agosto de 2008:

En el año de 1980 cuando mi Padre Emilio Hasbun y mi Hermano venían en un avión hacia Medellín y entrando al Valle de Aburrá se estrellan contra El Cerro del Padre Amaya, en la cual fallecen mi Padre, mi Hermano los dos pilotos y como 6 empresarios más todos amigos de la región de Urabá, a raíz de ese accidente el cambio familiar directamente me afectó a mí fue más parte de la no culminación de los estudios en el colegio el accidente de mi Padre nos tocó empezar a manejar todo lo que mi Padre dejó en Urabá, las bananeras, la finca ganadera, una maquinaria unos lotes en Apartadó, casas, oficinas, a raíz de eso Alejandro y yo nos repartimos el trabajo él se dedicó a lo que era la sucesión de mi papá y a manejar lo que eran la fincas bananeras y la representación de esas fincas bananeras en Uniban y Augura, por el número de hectáreas se tenía el número de votos que se necesitaban para hacer miembros de la junta directiva de Augura, creo que participo en eso se dedicó también a todo lo que era el tema con los abogados de la sucesión de mi papá ya que era socio de unos Hermanos del y de mi abuela todo lo que denominamos los Hasbun de Barranquilla, que la familia por el lado de mi papá yo me dedique a manejar la parte de ganadería sobre la carretera Panamericana y una maquinaria propiedades que dejó en la zona de Uraba, en el tema ganadero empecé a manejar una finca específicamente ubicada en la carretera Panamericana que se Ilama El Cocuelo, durante muchos años me acompañaba un Señor por la inexperiencia en el manejo de fincas, un amigo que se llama José González Chepe, un Sr. de 60 años de edad era el que me asesoraba y me dirigía en la parte de administración de la fincas ganaderas, era muy administrador del tema desde esa oportunidad en el año 80 empezamos, a mí me tocaba negociar con la guerrilla de las FARC, ELN, EPL, negociar las cuotas de la vacuna que nos exigía la guerrilla para poder hacer presencia nosotros en la parte administrativa que no nos robaran el ganado, que no lo ma- 
taran los administradores, que no invadieran la fincas, la entrada era demasiado difícil en el sentido que la carretera la ubicación de esa finca es una sola vía y la guerrilla permanentemente mantenía retenes mantenían el control o el registro de las personas que entrábamos y salíamos, había un Comandante guerrillero que manejaba la parte de los teléfonos, el único medio de comunicación en la zona este Sr. era muy amigo del Sr. que comente al principio Chepe y nos mantenía muy informados de que procedimientos había en contra de la finca y específicamente de nosotros, inicialmente uno de esos vecinos se llamaba Luis Rendón, él era contratista y trabajaba en la finca no es el guerrillero que tenía el lindero este Sr. fue dado de baja por un Señor por un Señor Miguel o Manuel Peñaranda que le robó la finca la que se llamaba Palma Real, vecino de él nos tocó soportar de parte de él un intento de secuestro de la finca eso fue en el año 82 o 83 no recuerdo bien, la tala permanente de árboles la finca tenía una parte en potreros ya trabajados y otro en montaña lo que llamamos nosotros una reserva ecológica en los linderos este Sr. se dedicaba permanentemente a no dejar trabajar, cortar los árboles a tratar de molestar lo más que pudiera me imagino con la filosofía de sacarnos de la zona, se robaban el ganado 10 2 animales semanales que el mismo Peñaranda con otro Sr. de la guerrilla permanentemente robaban ganado en la finca los sacrificaban dentro de la finca y lo repartían entre la comunidad, una parte la usaban ellos y otra para la comunidad, el amedrentamiento permanente de la guerrilla molestando.

En este relato se nos muestra al industrial y al comerciante que surge como consecuencia de los eventos negativos que le tocó vivir. Después de la muerte del padre, el hijo se ve obligado a sacar adelante los negocios, incluso con la ayuda de un señor mayor, dada su inexperiencia. A las circunstancias adversas producto del accidente aéreo y pese al trabajo que debe realizar, el hijo es víctima de la guerrilla, que no deja trabajar, que se roba el ganado, en fin, que se la pasa amedrentando a la población. El victimario se presenta como víctima, y los crímenes cometidos como resultado de esas circunstancias adversas que le correspondió vivir.

Por su parte, Evert Veloza, también conocido como H. H., en su versión del 29 de octubre de 2007 justifica la creación del Bloque Bananero como resultado de la existencia de la guerrilla del EPL y de las FARC en la zona:

La motivación del bloque bananero, fue el inicio totalmente de antisubversivo, fue creado por los hermanos CASTAÑo, en la zona de Córdoba y después enviado a la Zona de Urabá con el fin de combatir las guerrillas comunistas que hacían presencia en la zona de Urabá, como eran la EPL y las FARC.

Y su vinculación a las Auc se da como resultado de esos abusos:

Primero que todo, voy a hacer un relato de mis actividades antes de pertenecer a las autodefensas, vengo de una familia de clase media baja, mi padre mecánico, con 10 hijos, mi niñez la viví en el Valle del Cauca, en el Meta, después fuimos a dar en Urabá donde mi padre era mecánico y unos hermanos míos transportadores, terminando yo también manejando un camión, cargando plátano en la zona de Urabá hacia los embarcadores de Macondo y Zungo. 
Vivíamos en la zona de Urabá donde estaba dominada totalmente por el quinto frente de las Farc, por el Epl, donde dificultaba hasta nuestro trabajo que era transportar plátano hasta la zona de embarque; por cosas de la vida en Urabá también, como es conocido es una zona de mucho... en esa época de mucho contrabando, nosotros en el camión también cargábamos contrabando, en un viaje que cargué de Turbo a Medellín, se me roban el camión, saliendo de Turbo... Las Farc, viendo que era el último sustento, el único sustento que teníamos nosotros para poder sobrevivir, en la noche conociendo la zona y sabiendo el sitio donde tenían el camión, tomé el riesgo de entrar y sacar el camión de donde lo tenían ya descargado la guerrilla e irme para Medellín. Me voy para Medellín y ya no pude regresar a la zona de Urabá porque supe que si regresaba, los señores milicianos de las Farc me iban a matar por haberme llevado el camión, me fui para los Llanos Orientales a trabajar en el camión por allá, en nuestra vida de mi padre mecánico, conocimos una familia del dos, la familia de un señor álvarez, don FABIO álvAREZ, este Señor tenía un hijo en el Epl, este señor tenía una finca en el dos y repartía leche en el pueblo, llegaba todos los días a donde estaba mi papá, se hizo muy amigo de la familia, el hijo de este señor que era guerrillero del Epl, se vuela de la guerrilla, por cosas de la vida va a dar a donde estábamos nosotros en Acacías (Meta) trabajando cargando arroz, este señor ÁlVAREZ, tenía otros hijos, tenía hijos en dos matrimonios, en uno de estos matrimonios, era una mujer que estaba viviendo o casada con un primo de los CASTAÑo, le decían EL FLACO, entonces este señor, primo de los castaños llama a GABRIEL y le dice: que ya que el trabajo, era del Epl o había sido del Epl, los castaños les interesaba que trabajara con ellos porque tenían un proyecto de entrar una gente a la zona de Urabá; y que querían tener la oportunidad de tenerlo a él ahí porque él conocía la zona y que conocía como funcionaba la guerrilla en la zona de Urabá; este muchacho me convida, yo por necesidad, por falta de oportunidades en la vida, por falta de trabajo, porque el camión nuestro era un camión viejo, era un camión donde no podíamos viajar largo, porque, no nos daba por lo viejo... entonces por física y plena necesidad, como creo que en un 90 o 95\% de todos los muchachos o personas que han ingresado a las Autodefensas o a la guerrilla han ingresado por necesidad y por hambre. No creo que un porcentaje muy alto de las personas que han vinculado a estos grupos armados lo hagan por convicción propia o por una causa, la causa se va asumiendo después, se va uno responsabilizando y va asumiendo responsabilidades con la organización a la que pertenece, pero en el inicio, iniciamos por necesidad, por falta de oportunidad en este País, por falta de empleo en este País, lamentablemente, la guerra en este País se volvió una bolsa de empleo.

En este relato el autor de los crímenes se priva de toda agencia. Su vinculación es el resultado de los abusos de la guerrilla que le roba el camión y que luego de recuperarlo le impide trabajar en la zona. En este caso Veloza hace un relato heroico, se presenta como un individuo que lucha por salvar su camión y su fuente de trabajo y cuya vinculación a las Auc es el resultado de los abusos de las FarC y del ELN.

Este tipo de relato heroico en el que los sujetos se ven forzados a acudir a la violencia se repite en el texto de Ramón Isaza en que conmemora los 27 años de las Auc. Isaza en una carta abierta ha indicado cuál es el origen de las autode- 
fensas en el Magdalena Medio. En esta carta señala:

Un 22 de febrero del año 1978, hace ya 27 años, a la vereda la Estrella, del Corregimiento La Merced o Las Mercedes, como se le conoce comúnmente, en aquel entonces jurisdicción del Municipio de San Luís (Antioquia), hoy de Puerto Triunfo, incursionó una patrulla del noveno frente de las FARC, esta vez con órdenes específicas de asesinar a varias personas, a quienes acusaban de colaborar con el ejército, y como retaliación, porque no les colaboraban con ganado vacuno, o porcino, o con aves de corral, con dinero o con hijos para reclutarlos. En la lista me encontraba yo, Ramón Isaza, por ese entonces líder comunitario, concejal en San Luís, en representación de Puerto Triunfo.

En otras ocasiones habían llegado, las primeras, a manera de visita informativa, luego a que se les colaborara con animales o dinero, más tarde se llevaban los animales, o los mataban ahí mismo sin informar siquiera. Esto había sembrado el descontento entre los habitantes de la vereda y algunas medidas que se tomaron hacían prever que alguna de esas visitas tendría un desenlace fatal. Analizando eso en conversaciones que tuve con los vecinos, decidimos buscar ayuda y agruparnos para defendernos, para defender la vereda. Como ya se habían contactado en otras oportunidades con el ejército, decidimos entonces ir a buscar ayuda, esta vez, no para que mandaran patruIlas hasta la vereda, sino para que nos dieran armas para nosotros mismos hacerles frente, en caso de algún ataque que no diera tiempo de avisar. Ya en la, por aquel entonces base Calderón, ubicada cerca a Puerto Boyacá, con otros amigos expusimos la situación al Comandante de la base y luego de mucho hablar y recibir algunas instrucciones, nos entregaron 8 escopetas, de varios calibres, con suficientes cartuchos, ellas no en muy buen estado, porque eran de las decomisadas a las personas que no tenían permiso para portarlas, las cuales repartimos entre quienes nos habíamos comprometido a conformar este grupo para autodefendernos y no sufrir más el chantaje, la intimidación y el saqueo a que nos estaban sometiendo y que menguaba gravemente la economía de nuestros hogares.

Ese 22 de febrero, la sorpresa para las FARC, fue grande, "fueron por lana y salieron trasquilados", pues no lograron su cometido, pero en cambio sí perdieron 3 hombres en ese momento y luego otro, de los 7 que se llevaron heridos. Fue ese el primer combate librado por los valerosos hombres de esta vereda contra la guerrilla, y ese día nacieron las AutOdefENSAS CAMPESINAS, las que este próximo martes arriban a los 27 años de existencia. Ese día, será especial porque dos acontecimientos se unen en el tiempo: el último año de existencia de las Autodefensas, como grupo armado, y el primero designado como día oficial de ellas, de modo que las generaciones futuras recuerden esta fecha como una de las más importantes para nuestro país en materia de paz. ${ }^{10}$

\section{CONCLUSIÓN: LOS LÍMITES DE LA VERDAD JUDICIAL COMO MEMORIA HISTÓRICA}

Los relatos de los desmovilizados de las AUC no solo se ocupan de dar cuenta de los homicidios cometidos por la organización, sino que presen-

10 http://www.verdadabierta.com/la-historia/136-27-anos-de-lucha-porla-paz-?format=pdf. Última visita, 6 de noviembre de 2013. 
tan una justificación de los hechos o, como en el caso de Ramón Isaza, deciden adoptar la estrategia del olvido y aducir un supuesto Alzheimer que conduce a la pérdida de la memoria. En los relatos lo que encontramos, en la mayor parte, es el reconocimiento de responsabilidad por línea de mando, esto es, la aceptación de los cargos pero sin ninguna contribución significativa a la verdad.

Si bien en algunos casos se han entregado restos de las personas desaparecidas, lo cierto es que la contribución de los procesos de justicia y paz a una mayor información en este sentido no ha sido totalmente satisfactoria. Las víctimas, en un alto porcentaje, desconocen las razones por las cuales se cometió el delito, o el paradero de sus familiares, y en la mayor parte todo esto junto.

El proceso de justicia y paz se ha centrado de manera exagerada en el relato del victimario, que como vimos, está elaborado con contenidos heroicos y justificatorios. La versión de las víctimas es escuchada solo de manera excepcional y, en todo caso, no determina el curso de la investigación, como sí lo hace el relato del postulado.

La verdad producto de estos procesos es una verdad estratégica, interesada y cargada de actos heroicos. Su contribución a la verdad del conflicto está marcada por ese carácter unilateral. En esta medida, su aporte a la memoria del conflicto está marcado por esa limitación y por ese déficit democrático. Si la verdad judicial es el resultado de un procedimiento de confron- tación, en el proceso de justicia y paz tenemos una verdad producto del interés del postulado de dejar su versión para la historia, por tanto, su contribución como mecanismo de justicia de transición es bastante limitado, pues revictimiza a las víctimas y las somete nuevamente al silencio. De este modo se revive el acto de victimización en el que el victimario tiene todo el poder de la palabra y la víctima es privada de la posibilidad de hablar y de reclamar justicia.

\section{Referencias}

Aguilar, P. (1996). Aproximaciones teóricas y analíticas al concepto de memoria histórica de la guerra civil española (1936-1939). Madrid: Instituto Universitario Ortega y Gasset.

Aguilar, P. (2008). Políticas de la memoria y memorias de la política. Madrid: Alianza Editorial.

Akhavan, P. (November, 1998). Justice in The Hague. Peace in the Former Yugoslavia? Human Rights Quarterly, 20(4), 739-816.

Anten, L. (2009a). Fragile States: State Building is not Enough. En J. D Zwaan, E. Bakker y S. van der Meer (eds). Challenges in a Changing World. The Hague: T.M.C. Asser Press. Recuperado de http://www.clingendael.nl/ staff/publications.html?id=404

Anten, L. (2009b). Strengthening Governance in Post-conflict Fragile States. Issue Paper. The Hague: Netherlands Institute of International Relations. 
Barsalau, J. y Baxter, V. (January, 2007). The urge to remember. The role of memorials in Social Reconstruction and Transitional Justice. En Stabilization and Reconstruction Series, $n^{\circ}$. 5. Washington: United States Institute for Peace.

Benavides Vanegas, F. S. (2004). Hermeneutic Violence: Human Rights, Law, and the constitution of a global identity. International Journal for the Semiotics of Law.

Benavides Vanegas, F. S. (2006). The inclusive/exclusive Nation: Blacks and Indigenous peoples in the construction of the nation in Colombia. En A. Wagner, D. Cao y W. Wouter (eds). Interpretation, Law, and the construction of meaning. Collected Papers on Legal Interpretation in Theory, Adjudication and Political Practice. London: Springer.

Benavides Vanegas, F. S. (2013). Justicia en épocas de transición. Conceptos, modelos, debates y experiencias. Bogotá: Editorial Jurídica Gustavo Ibáñez.

Benavides Vanegas, F. S. y Ospina, A. M. (2013). El largo camino hacia la paz. Procesos e iniciativas de paz en Colombia y en Ecuador. Bogotá: Editorial Jurídica Gustavo Ibáñez.

Bergalli, R. (2010). Memoria colectiva como deber social. Barcelona: Anthropos.

Bergalli, R. (2012). Filosofía del mal y memoria colectiva: conceptos, aplicaciones e identidad social. Europa, Latinoamérica. El caso español. En A, Forero et al. Filosofía del mal y memoria. Barcelona: Anthropos.

Bickford, L. (2007). Unofficial Truth Projects. Human Rights Quarterly, 29, 994-1035.

Bickford, L. (November, 1999). The Archival Imperative: Human Rights and Historical Memory in Latin America's Southern Cone. Human Rights Quarterly, 21(4), 1097-1122.

Bietti, L. M. (2011). Memory, Discourse and Interaction. Tesi Doctoral Universitat Pompeu Fabra. Barcelona.

Bietti, L. M. (Abril, 2008). Memoria, violencia y casualidad en la Teoría de los Dos Demonios. El Norte. Finish Journal of Latin American Studies, 3. Recuperado de http://www. elnorte.fi/archive/2008-3/2008_3_elnorte_bietti.pdf.

Ereshnee, N. (August, 2006). The ties that bind: strengthening the links between memorialisation and transicional justice. TJP Research Brief. Centre for the Study of Violence and Reconciliation.

García Amado, J. A. (1997). La filosofía del derecho de Habermas y Luhmann. Bogotá: Universidad Externado de Colombia.

Goldman, F. (2008). The art of political murder: who killed the Bishop. New York: Grove Press.

Gutiérrez, C. B. (1983). El concepto de verdad en Heidegger. Confrontación de la Crítica de Tugenhat. Ideas y Valores, 32(61). 
Habermas, J. (1998). Teoría de la acción comunicativa. Madrid: Taurus Ediciones.

Hocket, J. D. (1990). Justice Robert H. Jackson, the Supreme Court, and the Nuremberg Trial. The Supreme Court Review, vol. 1990, 257299.

Human Rights Watch. (2009). Selling Justice Short. Why accountability matters for peace. New York: Autor.

Jackson, R. H. (21 November, 1945). Opening Statement for the prosecution. Recuperado de http://www.law.umkc.edu/faculty/projects/ftrials/nuremberg/jackson.html.

Jakobs, G. (Febrero, 1994). ¿Superación del pasado mediante el derecho penal? Acerca de la capacidad de rendimiento del derecho penal tras una fractura del régimen político. Anuario de Derecho Penal y Ciencias Penales, 47, 137-158.

Jelin, E. (2002). Los trabajos de la memoria. Madrid: Siglo XXI Editores, Social Science Research Council.

Miguez Macho, A. (2012). Nuestro pasado presente: práctica genocida y franquismo. Hispania Nova, 10. Recuperado de http://hispanianova.rediris.es/10/dossier/10d010.pdf.

Osiel, M. (February, 2000). Why Prosecute? Critics of Punishment for Mass Atrocity. Human Rights Quarterly, 22(1), 118-147.

Ospina, A. M. (2013). Memoria y construcción de paz: el trabajo del Grupo de Memoria Histó- rica de la Comisión Nacional de Reparación y Reconciliación. En F. S. Benavides Vanegas y A. M. Ospina. El largo camino hacia la paz. Procesos e iniciativas de paz en Colombia y en Ecuador. Bogotá: Editorial Jurídica Gustavo Ibáñez.

Payne, L. A. (2008). Unsettling accounts. Neither truth nor reconciliation in confessions of state violence. Durham: Duke University Press.

Payne, L. A. (2009). Epílogo a testimonios perturbadores. Ni verdad ni reconciliación en las confesiones de violencia de Estado. Bogotá: Universidad de los Andes.

Radbruch, G. (1962). Arbitrariedad legal y derecho supralegal. Buenos Aires: AbeledoPerrot.

Smith, A. D. (2000). Myths and Memories of the Nation. Oxford: Oxford University Press.

Teitel, R. G. (2000). Transitional Justice. Oxford: Oxford University Press.

Teitel, R. G. (2003). Transitional Justice Genealogy. Harvard Human Rights Law Journal, 16, 69-94.

Weigend, T. (2003). Is the Criminal Process about Truth? A German Perspective. Harvard Journal of Law and Public Policy, 157.

Weigend, T. (2010). Should we search for the truth; and who should do it? N.C.J. International Law \& Com. Reg., XXXVI. 